\title{
Adhesiveness of bulk-fill composite resin in permanent molars submitted to Streptococcus mutans biofilm
}

\author{
Tatiana Kelly da Silva FIDALGO(a) \\ Gabriela AMERICANO(a) (i) \\ Debora MEDINA(a) \\ Glaucia ATHAYDE(a) \\ Aline dos Santos LETIERI (b) \\ Lucianne Cople MAIA(b) \\ (a) Universidade do Estado do Rio de Janeiro \\ - UERJ, Dental School, Department of \\ Preventive and Community Dentistry, Rio de \\ Janeiro, RJ, Brazil. \\ (b) Universidade Federal do Rio de Janeiro \\ - UFRJ, Dental School, Department of \\ Pediatric Dentistry and Orthodontics, Rio de \\ Janeiro, RJ, Brazil.
}

Declaration of Interests: The authors certify that they have no commercial or associative interest that represents a conflict of interest in connection with the manuscript.

Corresponding Author:

Tatiana Kelly da Silva Fidalgo

E-mail: tatianaksfidalgo@gmail.com

hitps://doi.org/10.1590/1807-3107bor-2019.vol33.011 1

Submitted: June 2, 2019

Accepted for publication: October 9, 2019

Last revision: October 24, 2019
Abstract: The aim of the present study was to evaluate the microtensile bond strength and the microleakage of a bulk-fill composite resin compared with a conventional incremental composite resin, in permanent molars and under cariogenic challenge using a Streptococcus mutans model. Permanent human third molars $(\mathrm{n}=60)$ with an occlusal cavity of $5 \times 3 \times 2 \mathrm{~mm}$ were randomly allocated into four subgroups of restorative treatments: conventional composite resin with $(n=15)$ and without $(n=15)$ cariogenic challenge (Z350-E and Z350-C experimental and control groups, respectively), and bulk-fill composite resin with $(n=15)$ and without $(n=15)$ cariogenic challenge (Bulk Fill-E and Bulk Fill-C, respectively). Ten specimens from each subgroup were submitted to microtensile strength, and 5, to microleakage. The cariogenic challenge was conducted using the Streptococcus mutans strain (ATCC) for 7 days. The stickers obtained $(1 \times 1 \times 2 \mathrm{~mm})$ were submitted to a microtensile strength test, followed by classification of the fracture mode. Microleakage was performed using a scoring system. The data were analyzed by Kruskal-Wallis and Mann-Whitney tests $(p<0.05)$. Filtek Z350 XT resin presented higher microtensile bond strength than Bulk Fill resin without $(19.02 \pm 4.90$ and $8.76 \pm 3.94 \mathrm{MPa}$, respectively; $\mathrm{p}<0.001)$ and with cariogenic challenge $(22.69 \pm 7.86$ and $13.31 \pm 3.38 \mathrm{MPa}$, respectively; $\mathrm{p}<0.02)$. Z350-C and Bulk Fill-C resins presented a higher prevalence of mixed fractures (23 and $14 \%$, respectively) in the specimens submitted to cariogenic challenge than those of the control groups, whereas microleakage was similar $(p=0.85)$. The conventional composite resin had higher microtensile bond strength than the bulk-fill resin, but both resin types had similar adhesion quality and microfiltration scores.

Keywords: Dental Leakage; Streptococcus mutans; Dental Caries.

\section{Introduction}

Composite resins have posed many problems ever since they were introduced in routine clinical practice, including polymerization contraction, lack of adaptation to cavity walls, sensitivity, pulpitis, fracture and restoration loss. ${ }^{1,2}$ This concern has called for solutions to overcome its disadvantages by improving its properties and its insertion techniques. ${ }^{1,2,3}$ The most widely accepted insertion technique 
available uses increments. ${ }^{4}$ However, it has some disadvantages, such as incorporation of empty space, contamination and non-adhesion of layers, difficulty of incremental insertion in smaller preparations, and greater time needed for insertion and polymerization of each increment. ${ }^{4,5}$

Bulk-fill resins were developed as an alternative to conventional resins, inserted with up to $2 \mathrm{~mm}$ increments, because the bulk-fill variety features effective photopolymerization in increments of up to $4 \mathrm{~mm} .^{3}$ These $4-\mathrm{mm}$ increments gained the attention of pediatric professionals in their dental practice, because of the shorter clinical time associated with reduced shrinkage. When used in routine practice, bulk-fill resins present advantages compared with conventional resins, owing to their reduced, uncompromised clinical time, like polymerization contraction. If the polymerization from light curing does not penetrate the full depth of the resin, the unlinked monomers interact with saliva, thus compromising the physical properties of the resin and the integrity of the interface. ${ }^{6,7,8}$ This undesired result has already been dealt with by making bulk-fill resins translucent, thus allowing light to penetrate up to a thickness of 4 $\mathrm{mm}$, and reducing microleakage. ${ }^{9}$ Despite the wellknown benefits of bulk-fill resins, this composite resin must necessarily have physical-mechanical properties similar to conventional composite resins. ${ }^{10}$ Several studies have observed that bulkfill resins show average microtensile bond strength comparable or superior to conventional enamel or dentin composites of deciduous or permanent teeth; however, bulk-fill resins have been found to have more gaps in formation along gingival walls than conventional resins. ${ }^{11,12,13}$

The changes in bulk-resin adhesiveness after restoration are related to interface deterioration, a notably complex phenomenon. This process, in vivo, depends on physical factors, such as masticatory forces, expansion and contraction from thermal modification, enzymatic action and $\mathrm{pH}$ alteration from biofilm colonization. ${ }^{14,15,16,17,18}$ Although studies have shown that microtensile bond strength and microleakage along axial walls is better with bulkfill than conventional resins, scientific knowledge is still limited concerning the adhesive properties of these materials under critical $\mathrm{pH}$, a method used to stimulate the cariogenic challenge. ${ }^{19,20,21}$ The cariogenic challenge that occurs in the oral environment is complex, and several consortia of microorganism are required. ${ }^{22}$ In this respect, $\mathrm{pH}$ cycling is largely used to simulate a cariogenic challenge; however, this method is limited to $\mathrm{pH}$ variations, and fails to reproduce some biological characteristics, such as enzymatic degradation by oral microorganisms of collagen unprotected by adhesive. ${ }^{23,24}$ For this reason, models containing multiple or single specimens are well accepted. ${ }^{25,26}$ Therefore, the objective of this study was to evaluate the microtensile bond strength and the microleakage of bulk-fill resins in permanent teeth under cariogenic challenge, using a microbiologic model.

\section{Methodology}

This study was approved by the Local Ethics Committee (78555317.2.0000.5289). The research was conducted in full compliance with the World Medical Association Declaration of Helsinki, and written consent was obtained for use of permanent third molars from each patient. In addition, this study complies with the CRIS (Checklist for Reporting In-vitro Studies) guideline. ${ }^{27}$

\section{Sample preparation}

Sixty permanent human immature third molars without any signs of carious lesion, developmental enamel defects or fracture were collected for this study. All the teeth had their roots cut off. A cavity was prepared $5 \mathrm{~mm}$ long by $3 \mathrm{~mm}$ wide and 2 $\mathrm{mm}$ deep into the dentin on the occlusal surface of each tooth, using a cylindrical bur (number 4103, KG Sorensen ${ }^{\circledR}$, Cotia, Brazil) under water cooling. The occlusal surfaces were brushed for $10 \mathrm{~s}$ with a pumice stone solution, and then washed for $10 \mathrm{~s}$. The enamel margins of the cavity were then etched with a 37\% phosphoric acid gel (Dentsply ${ }^{\circledR}$, Catanduva, Brazil) for $15 \mathrm{~s}$, rinsed for $30 \mathrm{~s}$ and then dried for $10 \mathrm{~s}$. Scotchbond Universal Adhesive - Selective Etch $\left(3 \mathrm{M}{ }^{\circledR}\right.$, St. Paul, USA) was actively applied for $20 \mathrm{~s}$ using a microbrush. After drying with an air jet for $5 \mathrm{~s}$, the 
adhesive was light-cured for $10 \mathrm{~s}$ using a LED cure light (3M ESPE ${ }^{\circledR}$, Sumaré, Brazil). Thirty randomly selected teeth were restored with Filtek Z350 XT $(3 \mathrm{M} \AA$, St. Paul, USA), a conventional resin, using the incremental technique, adding 5 increments $\sim 1 \mathrm{~mm}$. Another thirty randomly selected teeth were restored with Bulk Fill resin (3M ESPE ${ }^{\oplus}$, St. Paul, USA), in a single increment of $\sim 5 \mathrm{~mm}$. Both Filtek Z350 XT and Bulk Fill restorations were constructed $1.5 \mathrm{~mm}$ high and $1 \mathrm{~mm}$ above the top of the cavity, respectively. All the restorations were light-cured for $40 \mathrm{~s}$ using a LED cure light $(3 \mathrm{M} \circledast$, Sumaré-SP, Brazil). The details of composition and the clinical procedures are shown in Table 1 . The specimens were randomly allocated into four groups (G1, G2, G3 and G4) and each code of each group (Z350-Control, Z350-Experimental, Bulk Fill-Control, Bulk Fill-Experimental, respectively) was registered in an Excel file. The operator was not blinded to the restorative procedures, since the incremental techniques were different for the resins. Instead, the blind was performed during the microbiological challenge for composite resins, and during the adhesion tests.

\section{Microbiological cariogenic challenge model}

Each prepared specimen was sterilized by ultraviolet irradiation. After the restoration was completed, the control group specimens (C) were immersed in 1.5 milliliters of BHI culture (Brain Heart Infusion, Difco, USA), supplemented with $2 \%$ sucrose without microorganisms, for 7 days. The experimental groups (E) were submitted to Streptococcus mutans. The inoculum of American Type Culture Collection (ATCC) specimens of Streptococcus mutans ATCC 25175 was used. The bacteria were kept at $-20^{\circ} \mathrm{C}$ in tryptic soy broth (TSB; Oxoid, Hampshire, England) with $20 \%$ glycerol, and activated by transfer into BHI agar (Brain Heart Infusion, Difco, USA). They were incubated under microaerophilic conditions, at $37^{\circ} \mathrm{C}$ for $48 \mathrm{~h}$, in a candle jar. Five colony-forming units (CFU) were placed in the BHI broth medium (Brain Heart Infusion, Difco, USA) for 24h. Then, the bacteria cells were suspended, according to the $0.5 \mathrm{McFarland}$ protocol ${ }^{28}$ and the 0.5 scale, in BHI broth medium (Brain Heart Infusion, Difco, USA) supplemented with $2 \%$ sucrose. The specimens were inoculated with samples of approximately $5 \times 10^{6}$ cells/ml Streptococcus mutans ATCC (\#25175), and the culture was incubated at $37^{\circ} \mathrm{C}$ under microaerophilic conditions for 7 days. ${ }^{25}$ Following the 7 days, the enamel surface of all the specimens was viewed at 20x magnification using an optical microscope (Olympus SZ-ST Stereo Microscope, Japan), to confirm the presence of white spot lesions in both the control group and the experimental group. The distribution of teeth is detailed in Figure 1.

\section{Microtensile bond strength test}

The sample size was calculated based on the mean and standard deviation of microtensile strength obtained by Mandava et al., ${ }^{29}$ with a $95 \%$ confidence interval and a power of 0.80 . A sample size of 8

Table 1. Details of each restorative material, manufacturer and restoration protocol.

\begin{tabular}{|c|c|c|}
\hline Material & Filtek Z350 XT & Bulk Fill \\
\hline Batch number & 734190 & 693115 \\
\hline \multirow[b]{2}{*}{ Manufacturer } & 3M ESPE, St. Paul, USA & 3M ESPE, St. Paul, USA \\
\hline & Bis-GMA, UDMA, TEGDMA, and Bis-EMA(6) resins. & $\begin{array}{c}\text { AFM (dynamic stress-relieving monomer), AUDMA, } \\
\text { UDMA and 1, 12-dodecane-DMA. }\end{array}$ \\
\hline Composition & $\begin{array}{l}\text { The fillers are a combination of non-agglomerated/ } \\
\text { non-aggregated } 20 \mathrm{~nm} \text { silica filler, non-agglomerated/ } \\
\text { non-aggregated } 4 \text { to } 11 \mathrm{~nm} \text { zirconia filler, and } \\
\text { aggregated zirconia/silica cluster filler (comprised of } 20 \\
\text { nm silica and } 4 \text { to } 11 \mathrm{~nm} \text { zirconia particles). }\end{array}$ & $\begin{array}{l}\text { A non-agglomerated/non-aggregated } 20 \mathrm{~nm} \text { silica } \\
\text { filler, a non-agglomerated/non-aggregated } 4 \text { to } 11 \mathrm{~nm} \\
\text { zirconia filler, an aggregated zirconia/silica cluster filler } \\
\text { (comprised of } 20 \mathrm{~nm} \text { silica and } 4 \text { to } 11 \mathrm{~nm} \text { zirconia } \\
\text { particles) and an ytterbium trifluoride filler consisting of } \\
\text { agglomerate } 100 \mathrm{~nm} \text { particles. }\end{array}$ \\
\hline Application protocol & $\begin{array}{l}\text { Multi incremental technique }-5 \text { increments of } \sim 1 \mathrm{~mm} \\
\text { in each well was performed. After increment insertion, it } \\
\text { was light-cured for } 40 \mathrm{~s} \text { using a LED cure light. }\end{array}$ & $\begin{array}{l}\text { Single incremental technique - a single increment of } \\
\sim 5 \mathrm{~mm} \text { was performed. After increment insertion, it } \\
\text { was light-cured for } 40 \mathrm{~s} \text { using a LED cure light. }\end{array}$ \\
\hline
\end{tabular}




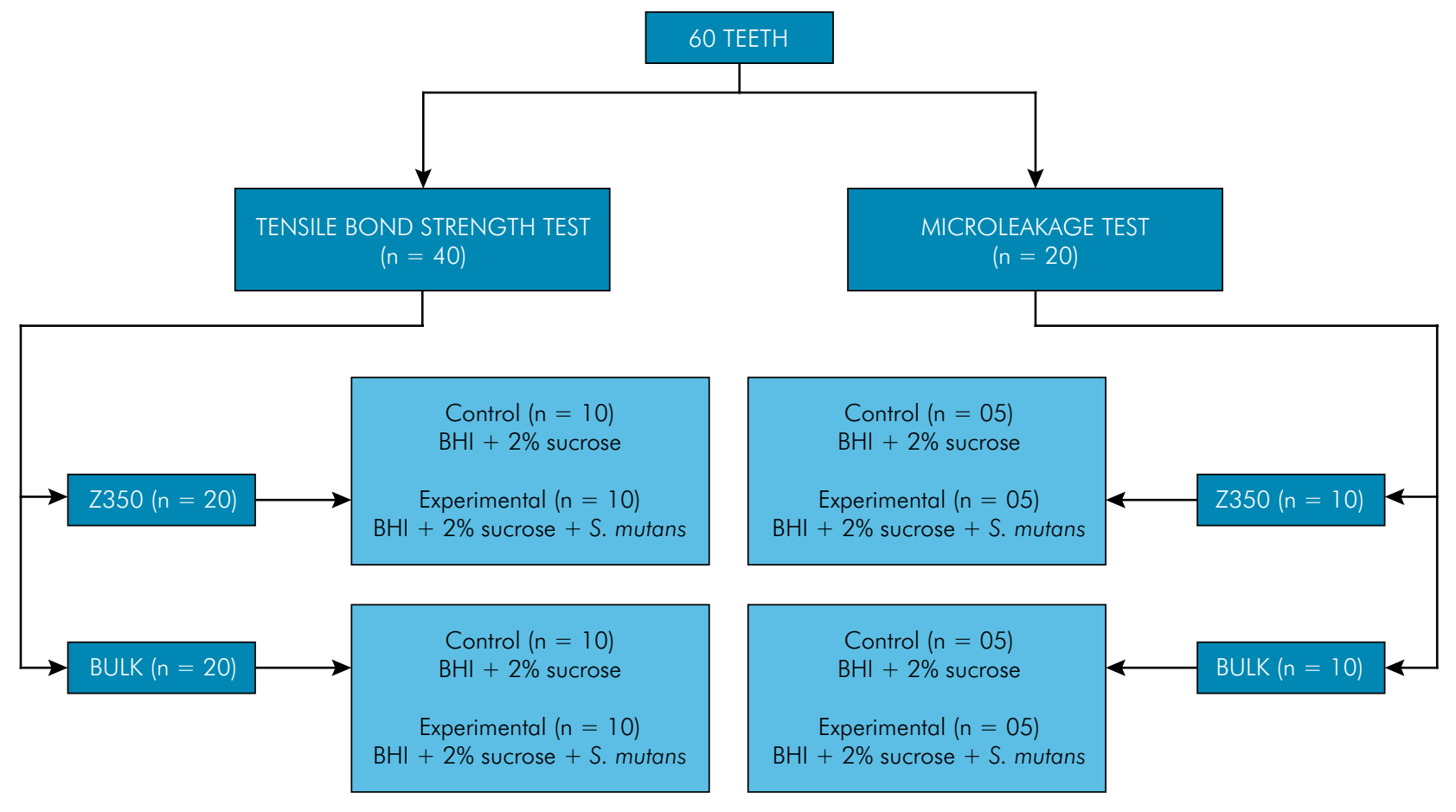

Figure 1. Flowchart of the study.

specimens per subgroup was obtained, and 30\% more specimens were included to offset the specimen loss. After the teeth were either submitted to the cariogenic challenge (experimental) or not (control), the specimens $(\mathrm{n}=10$, for each subgroup) were sectioned into 2 sticks ( $\mathrm{n}=13$, for each subgroup), according to the type of restorative material used (Filtek Z350 XT and Bulk Fill composite resin). The external sticks were discarded to avoid overexposure to Streptococcus mutans. The sticks measured $1 \mathrm{~mm}$ wide, $1 \mathrm{~mm}$ long and $2 \mathrm{~mm}$ deep; they were fixed in special devices with cyanoacrylate adhesive (Super Bonder ${ }^{\mathrm{TM}}$, Loctite, São Paulo, Brazil), after which a microtensile bond strength test was performed at a speed of 0.5 $\mathrm{mm} / \mathrm{min}$ in a universal testing machine (EMIC DL 2000, São José dos Campos, Brazil). Following the microtensile bond strength test, the fracture mode was examined by two independent calibrated (Kappa 0.97) examiners, and the fracture mode was classified as adhesive, cohesive or mixed (Figure 2).

\section{Microleakage test}

After remaining in storage, the microleakage test specimens $(n=20)$ restored with Filtek Z350 XT (control, $\mathrm{n}=5$ and experimental, $\mathrm{n}=5$ ) and Bulk Fill composite resin (control, $\mathrm{n}=5$ and experimental, $\mathrm{n}=5$ ) were immersed in a $50 \%$ aqueous silver nitrate solution for $24 \mathrm{~h}$ in a light-proof container. The teeth were then rinsed thoroughly in tap water and immersed in a vial containing a radiographic developer solution to reveal the silver nitrate, and allow the tracer-penetrated areas to be observed. The samples were sectioned longitudinally through the center of the restorations, using a diamond saw under water cooling (IsoMet, Buehler, Lake Bluff, USA).

The sectioned blocks were viewed in both mesial and distal planes ( $\mathrm{n}=10$, for each group) at 20x magnification, using an optical microscope (Olympus SZ-ST Stereo Microscope, Japan), by two independent examiners that graded the extent of tracer penetration at the resin-dentin interface, according to the following scoring system: $0=$ absence of dye penetration, $1=$ dye penetration up to one-half of the extension of the wall, 2 = dye penetration up to one half of the extension of the wall without reaching the axial angle, and $3=$ dye penetration across the whole extent of the wall. ${ }^{30}$ 

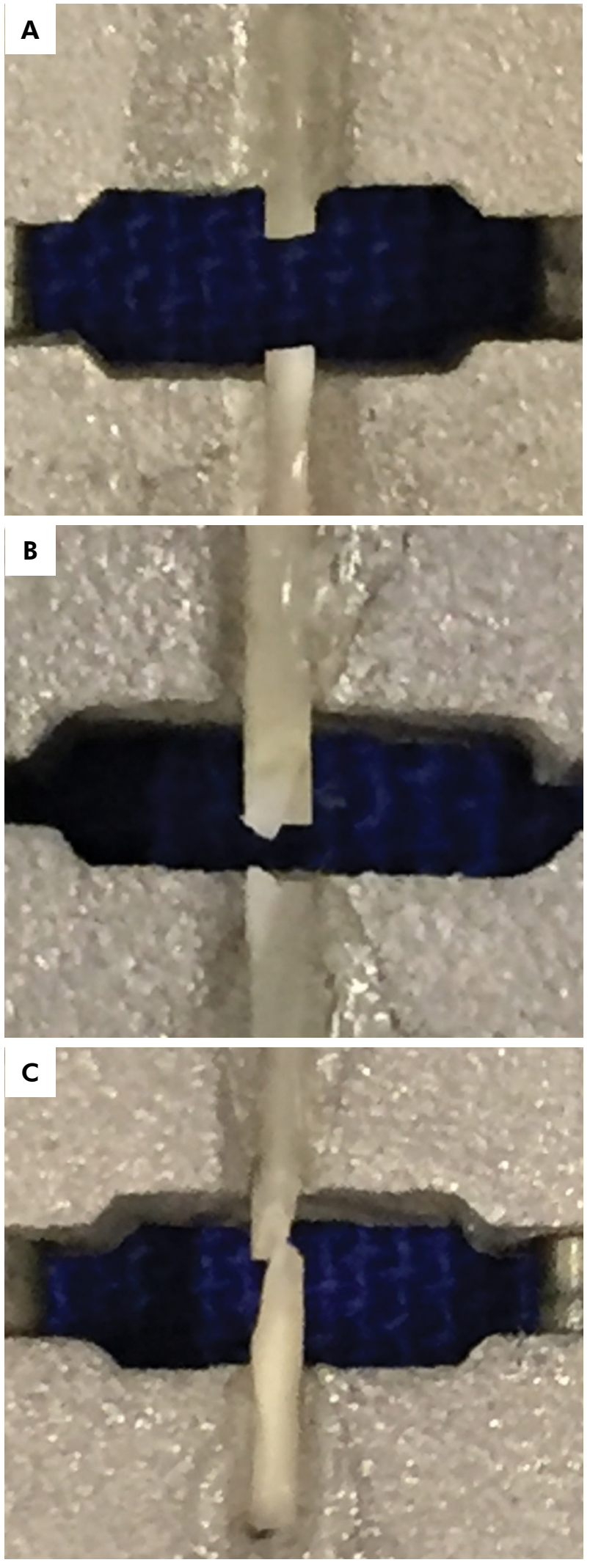

Figure 2. Representative images of fracture mode. AAdhesive, B-Cohesive and C-Mixed fractures.

\section{Statistical analysis}

Statistical analysis was performed using the Statistical Package for Social Sciences program, version 24.0 (SPSS Inc., IBM, Chicago, USA). The descriptive analysis included the calculation of bond strength mean values and standard deviations, as well as the percentage of each fracture type for Filtek Z350 XT and Bulk Fill groups, whether submitted or not submitted to the cariogenic challenge. Bond strength values, fracture modes and microleakage scores were analyzed using non-parametric tests, the Kruskal-Wallis test and the Mann-Whitney test with Bonferroni adjustments. The level of statistical significance was set at $5 \%$.

\section{Results}

At the end of the 7-day cariogenic challenge using the commercial strain of Streptococcus mutans, white spot lesions could be observed in all the permanent teeth of the experimental groups, demonstrating the validity of this cariogenic biofilm-based model.

\section{Microtensile bond strength test}

Figure 3 shows the bond strength values for the Filtek Z350 XT and Bulk Fill groups, whether submitted or not submitted to the cariogenic challenge. The

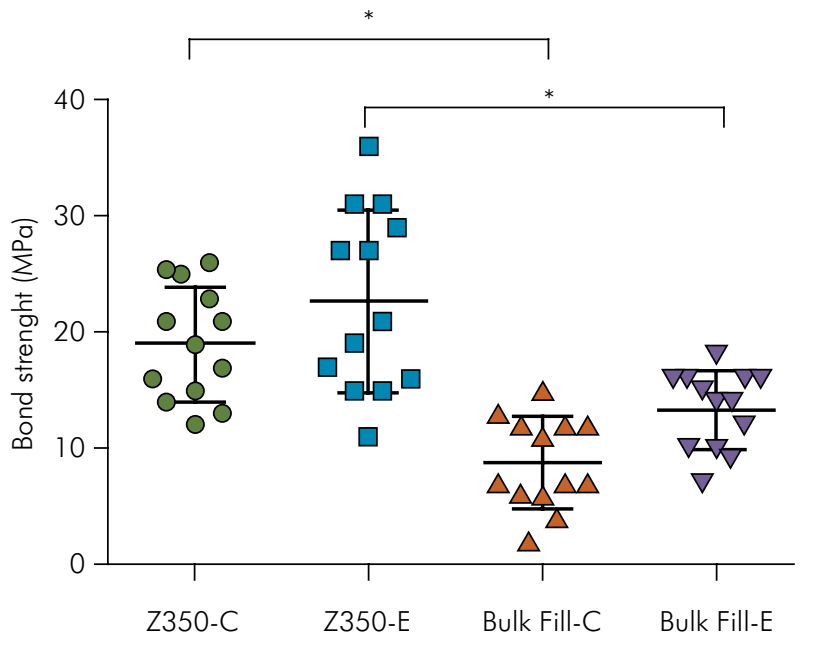

Figure 3. Means and standard deviations of control and experimental groups of the resin-dentin bond strength values $(\mathrm{MPa})$ and the statistical differences $\left({ }^{*}\right.$ means $\mathrm{p}<0.05$; KruskalWallis and Mann-Whitney tests). 
Kruskal-Wallis test showed a significant difference between the groups ( $p$ 0.001). Filtek Z350 XT resin had a higher mean bond strength than Bulk Fill resin, when not submitted to the cariogenic challenge $(19.02 \pm 4.90$ and $8.76 \pm 3.94 \mathrm{MPa}$, respectively; $\mathrm{p}<0.001)$, and also when submitted to the cariogenic challenge (22.69 \pm 7.86 and $13.31 \pm 3.38 \mathrm{MPa}$, respectively; $\mathrm{p}<0.02)$. The cariogenic challenge using the Streptococcus mutans model was not able to influence the bond strength values of different specimens within the same composite resin, conventional and bulk-fill $(\mathrm{p}>0.05)$.

Table 2 shows that the fracture mode presented no significant difference among the groups $(p=0.94)$. The adhesive and cohesive fracture modes had higher scores (38.5\%) for Z350-C, and a higher score for cohesive fractures (61.5\%) was observed in Z350-E. Bulk Fill-C also presented higher scores for adhesive and cohesive fractures (42.9\%), and Bulk Fill-E cohesive fracture scores were even higher (57.1\%) after undergoing the experimental conditions. A comparison of the different composite resins in the same experimental condition showed that they had similar scores. Z350-C and Bulk Fill-C presented a higher prevalence of mixed fractures (23 and 14\%, respectively); the mixed fracture mode decreased for both resins after the cariogenic challenge, thus
Z350-C and Bulk Fill-C had a lower prevalence of this fracture mode (7.7 and $7.2 \%$, respectively).

\section{Microleakage test}

Table 3 shows the scores for the groups. There was no difference among the groups $(p=0.85)$, regardless of the resin type or the cariogenic challenge. The results showed absence of silver nitrate penetration (score 0 ) in most of the samples of the groups, ranging from 50 to $70 \%$, and Z350-C had a higher prevalence of this score $(70 \%)$. In addition, there was a lower prevalence of microleakage up to one half of the extension of the wall without reaching the axial angle (score 2) in all the groups, ranging from 0 to 10\%. Z350-C and Bulk Fill-E presented the lowest prevalence of this score $(0 \%)$.

\section{Discussion}

In the present study, the conventional resin composite showed higher bond strength compared with the bulk-fill resin, in relation to the conditions of both the control group and the cariogenic challenge. In addition, the cariogenic condition did not influence the microtensile bond strength. Although bulkfill composite resins are known to have decreased microtensile bond strength, it is important to

Table 2. Percentage (\%) of failure mode.

\begin{tabular}{|c|c|c|c|c|}
\hline Failure & Z350 (Control) & Z350 (Experimental) & Bulk fill (Control) & Bulk fill (Experimental) \\
\hline Adhesive (\%) & $38.5^{a}$ & $30.8^{a}$ & $42.9^{\circ}$ & $35.7^{a}$ \\
\hline Cohesive (\%) & $38.5^{b}$ & $61.5^{b}$ & $42.9^{b}$ & $57.1^{\mathrm{b}}$ \\
\hline Mixed (\%) & $23.0^{c}$ & $7.7^{c}$ & $14.3^{c}$ & $7.2^{c}$ \\
\hline
\end{tabular}

No statistical difference was observed among the groups (Kruskal-Wallis and Mann-Whitney tests). ${ }^{a, b, c, d}$ Similar letters in the same line means no statistical difference $(p>0.05)$

Table 3. Percentage (\%) of microleakage distribution.

\begin{tabular}{lcccc}
\hline Microleakage & Z350 (Control) & Z350 (Experimental) & Bulk fill (Control) & Bulk fill (Experimental) \\
\hline Score $0(\%)$ & $70^{a}$ & $50^{a}$ & $60^{a}$ & $60^{a}$ \\
Score 1 (\%) & $20^{\mathrm{b}}$ & $30^{\mathrm{b}}$ & $10^{\mathrm{b}}$ & $10^{\mathrm{b}}$ \\
Score 2 $(\%)$ & $0^{\mathrm{c}}$ & $10^{\mathrm{c}}$ & $10^{c}$ & $0^{c}$ \\
Score 3 $(\%)$ & $10^{\mathrm{d}}$ & $10^{\mathrm{d}}$ & $20^{\mathrm{d}}$ & $30^{\mathrm{d}}$ \\
\hline
\end{tabular}

No statistical difference was observed among the groups (Kruskal-Wallis and Mann-Whitney tests). ${ }^{a, b, c, d}$ Similar letters in the same line means no statistical difference $(p>0.05)$. 
highlight that the values found in the present study were acceptable and compatible with conventional composite resins, thereby making them suitable for use in clinical practice. ${ }^{25}$ Bulk-fill resins have a low rate of infiltration of the adhesive; therefore, we can hypothesize that enzymatic degradation by oral microorganisms of collagen unprotected by adhesive were more prone to occur in the bulk-fill composite resin. ${ }^{23,24}$ However, the cariogenic challenge was unable to decrease the microtensile strength of the bulk-fill composite resin, because of the peculiarities of the cariogenic challenge model used. This model had no multi specimen biofilm, and acquired a pellicle of human saliva, which enabled it to promote efficient initial colonization of the enamel structure. Omar et al..$^{20}$ demonstrated that in vitro restorations using a conventional composite resin in caries-affected dentin were inferior to restorations in sound dentin. The difference in the results can be attributed to the difference in how the study was conducted, since the authors used extracted molars with dentin caries, 10 and did not produce it artificially, as was done in the present study. Our study corroborates the findings of Almeida Junior et al. ${ }^{31}$ the authors demonstrated that a group of conventional composite resins showed a higher bond strength when compared to a group of bulk-fill resins; this agrees with our findings. ${ }^{25}$

Our findings demonstrated that the most common fracture found in both the conventional Z350 and the Bulk Fill groups, under cariogenic challenge conditions, was the cohesive fracture. In addition, the adhesive and cohesive fracture modes were similar in the control groups of both resins. Flury et al. ${ }^{32}$ also demonstrated a higher prevalence of cohesive fractures for both conventional and bulk-fill composite resins, corroborating our findings. On the other hand, Ilie et al. ${ }^{12}$ demonstrated that both conventional and bulk-fill composite resins present a higher adhesive fracture mode (61.9\%), followed by the mixed fracture mode (38.1), in primary and permanent human teeth. This can be explained by the differences in the experimental conditions of the studies. The adhesive fracture mode showed the highest mechanical resistance of the composite resins, and the cohesive fracture mode suggests high adhesion. In the present study, the cariogenic challenge decreased the adhesive fracture percentages, and increased the mixed fracture percentages for the incremental conventional composite resin. As for the bulk-fill resin, the cariogenic challenge did not decrease the adhesive fracture rates.

To the best of our knowledge, this is the first time that the adhesion properties of bulk-fill composite resin have been assessed after being submitted to cariogenic conditions with Streptococcus mutans cells. The literature has largely explored the mechanical properties of bulk-fill composite resins, but these comparisons have generally been conducted in non-physiologic conditions, and in the absence of a cariogenic challenge. ${ }^{11,12,19-21}$ In the present study, Streptococcus mutans strains were used to induce a more biological cariogenic challenge than those brought about by $\mathrm{pH}$ cycling. ${ }^{25}$ The advantage of these biological models is the presence of the proteinases produced by the bacterial systems that induce secondary destruction in tooth protein, thus promoting faster induction of white spot lesions than $\mathrm{pH}$ cycling with artificial saliva, for example. ${ }^{33}$ However, the biofilm formation model using a single microorganism to induce a cryogenic challenge is largely accepted; the limitation of the present study was the absence of a multi-species biofilm, since dental caries is a polymicrobial disease caused by various consortia. ${ }^{22}$

The microleakage was similar in both conventional composite resins and bulk-fill resins. The majority of the resin samples in all of the groups showed no dye penetration (score 0 ). However, the experimental conditions of the present study were able to reduce the score of the conventional resins (score 0 ) and increase the score of the bulk-fill resins (score 3). Conventional single incremental composite resin presents considerable shrinkage during the polymerization process. Bulk-fill resins present a lower modulus of elasticity and lower wettability than conventional resins; therefore, better microleakage is expected. ${ }^{34}$ Microleakage is an important parameter of marginal adaptation, and directly influences the longevity of restorations; it can lead to the repair or replacement of the restoration, depending on how the restoration fails. ${ }^{35}$ In contrast, our findings showed that Bulk Fill did not present better microleakage; instead, it was 
similar to that of conventional resin. These findings corroborate those by Fronza et al., ${ }^{34}$ who found no microleakage differences between conventional and bulk-fill resin. In addition, Scotti et al. ${ }^{35}$ also demonstrated that conventional composite resin and bulk-fill resin showed similar microleakage values at the enamel margins.

Limitations of the present study were the single species biofilm using the Streptococcus mutans commercial strain, and also the absence of human saliva for biofilm formation. Human saliva presents a biological role during the initial colonization, and salivary proteins and glycoproteins comprise the acquired pellicle that is crucial to biofilm establishment. ${ }^{36}$ Cavalcanti et al. ${ }^{37}$ demonstrated that salivary pellicles modulate the virulence of Candida albicans biofilm, therefore demonstrating the importance of saliva during biofilm formation. In this respect, Mira et al. ${ }^{37}$ proposed an in vitro system for complex biofilm formation using different kinds of inoculum from oral samples, including saliva.

Although bulk-fill resins present the advantage of easy insertion into the dental cavity, the present study showed that bulk-fill resin presented lower microtensile bond strength, but similar fracture mode and microleakage, compared to conventional resin. In this respect, bulk-fill composite resin can be used instead of conventional resin in situations where chair time is crucial to the success of the treatment, such as during the dental treatment of children, and in restorations with controlled masticatory overload. This data suggests that clinicians should consider the benefits and the advantages of using bulk-fill resin when planning a composite resin restoration. More clinical trials are needed to evaluate the influence of the cariogenic challenge on bulk-fill composite resin performance, including trials using patients of different cariogenic severity.

\section{Conclusion}

This study demonstrates that conventional composite resins present a higher microtensile bond strength than bulk-fill resins, and similar adhesion quality and microleakage scores, regardless of the cariogenic challenge.

\section{Acknowledgments}

This study was financed in part by FAPERJ and CNPq.

\section{References}

1. Roggendorf MJ, Krämer N, Appelt A, Naumann M, Frankenberger R. Marginal quality of flowable 4-mm base vs. conventionally layered resin composite. J Dent. 2011 Oct;39(10):643-7. https://doi.org/10.1016/j.jdent.2011.07.004

2. Rullmann I, Schattenberg A, Marx M, Willershausen B, Ernst CP. Photoelastic determination of polymerization shrinkage stress in low-shrinkage resin composites. Schweiz Monatsschr Zahnmed. 2012;122(4):294-9.

3. Moorthy A, Hogg CH, Dowling AH, Grufferty BF, Benetti AR, Fleming GJ. Cuspal deflection and microleakage in premolar teeth restored with bulk-fill flowable resin-based composite base materials. J Dent. 2012 Jun;40(6):500-5. https://doi.org/10.1016/i.jdent.2012.02.015

4. Lazarchik DA, Hammond BD, Sikes CL, Looney SW, Rueggeberg FA. Hardness comparison of bulk-filled/transtooth and incrementalfilled/occlusally irradiated composite resins. J Prosthet Dent. 2007 Aug;98(2):129-40. https://doi.org/10.1016/S0022-3913(07)60046-8

5. Sarrett DC. Clinical challenges and the relevance of materials testing for posterior composite restorations. Dent Mater. 2005 Jan;21(1):9-20. https://doi.org/10.1016/i.dental.2004.10.001

6. Lindberg A, Emami N, van Dijken JW. A Fourier transform Raman spectroscopy analysis of the degree of conversion of a universal hybrid resin composite cured with light-emitting diode curing units. Swed Dent J. 2005;29(3):105-12.

7. Lindberg A, Peutzfeldt A, van Dijken JW. Effect of power density of curing unit, exposure duration, and light guide distance on composite depth of cure. Clin Oral Investig. 2005 Jun;9(2):71-6. https://doi.org/10.1007/s00784-005-0312-9

8. Michelsen VB, Kopperud HB, Lygre GB, Biörkman L, Jensen E, Kleven IS, et al. Detection and quantification of monomers in unstimulated whole saliva after treatment with resin-based composite fillings in vivo. Eur J Oral Sci. 2012 Feb;120(1):89-95. https://doi.org/10.1111/j.1600-0722.2011.00897.x

9. Zorzin J, Maier E, Harre S, Fey T, Belli R, Lohbaver U, et al. Bulk-fill resin composites: polymerization properties and extended light curing. Dent Mater. 2015 Mar;31(3):293-301. https://doi.org/10.1016/j.dental.2014.12.010 
10. Kruly PC, Giannini M, Pascotto RC, Tokubo LM, Suga US, Marques AC, et al. Meta-analysis of the clinical behavior of posterior direct resin restorations: low polymerization shrinkage resin in comparison to methacrylate composite resin. PLoS One. 2018 Feb;13(2):e0191942. https://doi.org/10.1371/journal.pone.0191942

11. Al-Harbi F, Kaisarly D, Michna A, ArRejaie A, Bader D, El Gezawi M. Cervical Interfacial Bonding Effectiveness of Class II Bulk Versus Incremental Fill Resin Composite Restorations. Oper Dent. 2015 Nov-Dec;40(6):622-35. https://doi.org/10.2341/14-152-L

12. Ilie N, Schöner C, Bücher K, Hickel R. An in-vitro assessment of the shear bond strength of bulk-fill resin composites to permanent and deciduous teeth. J Dent. 2014 Jul;42(7):850-5. https://doi.org/10.1016/i.jdent.2014.03.013

13. Miletic V, Peric D, Milosevic M, Manojlovic D, Mitrovic N. Local deformation fields and marginal integrity of sculptable bulk-fill, low-shrinkage and conventional composites. Dent Mater. 2016 Nov;32(11):1441-51. https://doi.org/10.1016/j.dental.2016.09.011

14. Nikaido T, Kunzelmann KH, Ogata M, Harada N, Yamaguchi S, Cox CF, et al. The in vitro dentin bond strengths of two adhesive systems in class I cavities of human molars. J Adhes Dent. 2002;4(1):31-9.

15. De Munck J, Van den Steen PE, Mine A, Van Landuyt KL, Poitevin A, Opdenakker G, et al. Inhibition of enzymatic degradation of adhesive-dentin interfaces. J Dent Res. 2009 Dec;88(12):1101-6. https://doi.org/10.1177/0022034509346952

16. Pashley DH, Tay FR, Yiu C, Hashimoto M, Breschi L, Carvalho RM, et al. Collagen degradation by host-derived enzymes during aging. J Dent Res. 2004 Mar;83(3):216-21. https://doi.org/10.1177/154405910408300306

17. Finer Y, Santerre JP. Salivary esterase activity and its association with the biodegradation of dental composites. J Dent Res. 2004 Jan;83(1):22-6. https://doi.org/10.1177/154405910408300105

18. Breschi L, Mazzoni A, Ruggeri A, Cadenaro M, Di Lenarda R, De Stefano Dorigo E. Dental adhesion review: aging and stability of the bonded interface. Dent Mater. 2008 Jan;24(1):90-101. https://doi.org/10.1016/i.dental.2007.02.009

19. Colak H, Ercan E, Hamidi MM. Shear bond strength of bulk-fill and nano-restorative materials to dentin. Eur J Dent. 2016 Jan-Mar;10(1):40-5. https://doi.org/10.4103/1305-7456.175697

20. Francois P, Vennat E, Le Goff S, Ruscassier N, Attal JP, Dursun E. Shear bond strength and interface analysis between a resin composite and a recent high-viscous glass ionomer cement bonded with various adhesive systems. Clin Oral Investig. 2019 Jun;23(6):2599-608. https://doi.org/10.1007/s00784-018-2678-5

21. Koç-Vural U, Kerimova L, Baltacioglu IH, Kiremitçi A. Bond strength of dental nanocomposites repaired with a bulkfill composite. J Clin Exp Dent. 2017 Mar;9(3):e437-42. https://doi.org/10.4317/jced.53501

22. Simón-Soro A, Mira A. Solving the etiology of dental caries. Trends Microbiol. 2015 Feb;23(2):76-82. https://doi.org/10.1016/j.tim.2014.10.010

23. Liu Y, Tiäderhane L, Breschi L, Mazzoni A, Li N, Mao J, et al. Limitations in bonding to dentin and experimental strategies to prevent bond degradation. J Dent Res. 2011 Aug;90(8):953-68. https://doi.org/10.1177/0022034510391799

24. Spencer P, Swafford JR. Unprotected protein at the dentin-adhesive interface. Quintessence Int. 1999 Jul;30(7):501-7.

25. Alencar NA, Fidalgo TK, Cajazeira MR, Maia LC. Influence of the number of adhesive layers on adhesive interface properties under cariogenic challenge using streptococcus mutans. J Adhes Dent. 2014 Aug;16(4):339-46. Htttps://doi.org/10.3290/i.jad.a32569

26. Paiva L, Fidalgo TKS, Costa LP, Maia LC, Balan L, Anselme K, et al. Antibacterial properties and compressive strength of new one-step preparation silver nanoparticles in glass ionomer cements (NanoAg-GIC). J Dent. 2018 Feb;69:102-9. https://doi.org/10.1016/i.jdent.2017.12.003

27. Krithikadatta J, Gopikrishna V, Datta M. CRIS Guidelines (Checklist for Reporting In-vitro Studies): A concept note on the need for standardized guidelines for improving quality and transparency in reporting in-vitro studies in experimental dental research. J Conserv Dent. 2014 Jul;17(4):301-4. https://doi.org/10.4103/0972-0707.136338

28. McFarland J. The nephelometer: An instrument for estimating the number of bacteria in suspensions used for calculating the opsonic index and for vaccines. JAMA. 1907;49(14):1176-78. https://doi.org/10.1001/jama.1907.25320140022001f

29. Mandava J, Vegesna DP, Ravi R, Boddeda MR, Uppalapati LV, Ghazanfaruddin MD. Microtensile bond strength of bulk-fill restorative composites to dentin. J Clin Exp Dent. 2017 Aug;9(8):e1023-8. https://doi.org/10.4317/jced.53965

30. Retief DH, Woods E, Jamison HC. Effect of cavosurface treatment on marginal leakage in class $\mathrm{V}$ composite resin restorations. J Prosthet Dent. 1982 May;47(5):496-501. https://doi.org/10.1016/0022-3913(82)90298-0

31. Mo SS, Bao W, Lai GY, Wang J, Li MY. The microfloral analysis of secondary caries biofilm around Class I and Class II composite and amalgam fillings. BMC Infec Dis. 2010 Aug;10:241. https://doi.org/10.1186/1471-2334-10-241

32. Marigo L, Spagnuolo G, Malara F, Martorana GE, Cordaro M, Lupi A, et al. Relation between conversion degree and cytotoxicity of a flowable bulk-fill and three conventional flowable resin-composites. Eur Rev Med Pharmacol Sci. 2015 Dec;19(23):4469-80.

33. Martins BMC, Silva EJNL, Ferreira DMTP, Reis KR, Fidalgo TKS. Longevity of defective direct restorations treated by minimally invasive techniques or complete replacement in permanent teeth: a systematic review. J Dent. 2018 Nov;78:22-30. https://doi.org/10.1016/i.jdent.2018.09.001

34. Fronza BM, Makishi P, Sadr A, Shimada Y, Sumi Y, Tagami J, et al. Evaluation of bulk-fill systems: microtensile bond strength and non-destructive imaging of marginal adaptation. Braz Oral Res. 2018;32:e80. https://doi.org/10.1590/1807-3107bor-2018.vol32.0080 
- Adhesiveness of bulk-fill composite resin in permanent molars submitted to Streptococcus mutans biofilm

35. Scotti N, Comba A, Gambino A, Paolino DS, Alovisi M, Pasqualini D, et al. Microleakage at enamel and dentin margins with a bulk fills flowable resin. Eur J Dent. 2014 Jan;8(1):1-8. https://doi.org/10.4103/1305-7456.126230

36. Lendenmann U, Grogan J, Oppenheim FG. Saliva and dental pellicle--a review. Adv Dent Res. 2000;14(1):22-8. https://doi.org/10.1177/08959374000140010301

37. Mira A, Buetas E, Rosier B, Mazurel D, Villanueva-Castellote Á, Llena C, et al. Development of an in vitro system to study oral biofilms in real time through impedance technology: validation and potential applications. J Oral Microbiol. 2019 May;11(1):1609838. https://doi.org/10.1080/20002297.2019.1609838 